\title{
The Role of the Teacher-Principal on Hutterite Colony Schools in Saskatchewan
}

\author{
William Randall Rodger ${ }^{1}$ \\ Adjunct Assistant Professor \\ Department of Educational Psychology and Leadership Studies \\ Faculty of Education \\ University of Victoria \\ Victoria, BC, Canada
}

\begin{abstract}
Hutterite colony teacher-principals' roles in their classrooms and schools were examined in this qualitative multiple-site case study. Four teacher-principals' perceptions of how their teaching and administrative responsibilities impacted their work/life and how the relationship contributed to tension between the two roles were studied. Pre-interviews, interviews (formal and informal), and classroom participation and observation occurred over four months. Three themes emerged from the study: (1) dealing with and balancing multiple roles on a daily basis; (2) the teachers' beliefs in the primacy of teaching; and (3) the daily impact of school division and provincial relationships. Rising educational expectations on the colonies, the impact of technology, growing school district and provincial accountability, and the diversity of students' needs have commanded an increasing proportion of the teachers' time, without the provision of additional supports. Two policy recommendations are made to the colony schools: (1) recruit teacherprincipals who exhibit cultural and relational competence; and (2) integrate teacher-principals into the district / administrative processes to provide the best support for colony schools.
\end{abstract}

\section{Key Words}

Dariusleut Hutterite; Teacher-principal; Colony school; One-room classroom; Cultural competence; Cross-cultural educational leadership 


\section{Introduction}

Hutterite schools are public schools located on the colony and served by public school teachers. Hutterites schools typically serve K-8 students up to 15 years of age. Because schools are small — often a one-room setting — most schools have only one teacher per colony school, although they may have the assistance of another teacher or an educational assistant. Consequently, with a recent increase in student, colony, school division, and provincial expectations, the colony teacher is experiencing an increased workload. Among these changes are an ever diversifying set of student educational demands, increasing administrative duties, and an awakening interest among Hutterites for instruction to Grade 12. Such changing circumstances, without a concomitant increase in support, creates a situation where public teachers experience overwork and under preparation.

This study focuses on teachers in Saskatchewan Hutterite colonies. Prompting this investigation, teacher strains are evident in Saskatchewan Hutterite colony schools in at least five ways. First, the teacher has twice the demands because of actually handling two roles. This "teacher-principal" combination role (1) is a full-time teacher and, (2) is required to fulfill the legal duties of a principal as defined by Saskatchewan's The Education Act. Principals must supervise the staff, coach and supervise instruction, assign tasks, prepare the school timetable and budget, order supplies, and complete numerous other administrative duties.

Second, the teacher-principal is usually the only teacher and is responsible for instructing all grades K-8. Certain instructional supports do provide some relief. Many schools have at least one other school staff member. And while the teacher-principal does spend much time in direct instruction, students may also spend time with the educational assistant or in on-line learning if the internet connection is available. In spite of this relief, the teacher-principal is still the one responsible for most instruction, educational organization, educational planning, and the overall welfare of the school.

Third, colonies, the school division, and the province are demanding higher grade levels, courses, and instructional strategies, compounding the teacher-principal's duties. For example, because some students are continuing their schooling past age 15, they are required to take driver education at school, a legal requirement in Saskatchewan. Aside from the in-car instruction (which requires the student to be absent from regular classroom instruction), a 30-hour classroom component must also be taught.

Fourth, the school division central office and the province has increased the accountability and responsibility of the teacher-principals, often without an increase of staff assistance. For example, the teacher-principal must learn new data entry programs to record information about students.

Fifth, no specific curriculum written for Hutterite schools in Saskatchewan exists. The two provincial universities do not offer dedicated courses addressing Hutterite education, and 
minimal direction is received from the Ministry of Education. Appropriate culture-specific instructional resources for Hutterite students are sparse and/or expensive, and relevant professional development opportunities for colony teachers are rare.

This study explores how teacher-principals are managing, coping with, and adjusting to the increased demands. Four colony teacher-principals were observed in their schools. Interview responses and observations of student interactions were summarized and analyzed to explore commonalities and differences among the four teachers.

\section{Research Design and Methodology}

To investigate how teacher-principals are managing, coping with, and adjusting to increased demands, data collection focused on how educational expectations have changed and how the role of the teacher-principal has expanded (Guthrie and Schuermann 2010). What are the factors - educational and otherwise - that have contributed to the teacher-principals' role strain?

To explore these changes, I conducted a multiple site case study of four Hutterite colony schools. These four are among eight Hutterite schools situated in a school division with 44 rural and suburban public schools with approximately 12,000 students. The colonies that house the eight Hutterite schools are members of the Dariusleut discipline, although cultural and social differences were evident among them. The four colonies were well-spaced geographically throughout the school division. The greatest distance between two colonies was approximately 150 kilometers. The four colony schools and the teachers were given pseudonyms for this study.

To narrow the school selection from eight to four, I used purposive sampling (Silverman 2004, 250). Purposive sampling is similar to criterion-based sampling whereby a list of the attributes required is constructed, then you look for those matching your specifications (Merriam 2009). Purposive sampling was appropriate because my objective "was not to generalize the findings of my study to the broad population but to maximize discovery of the heterogeneous patterns and problems occurring" on the four colonies (Erlandson, Harris, Skipper, and Allen 1993, 82).

I spent two weeks travelling to and visiting with each of the eight colony teacherprincipals in the school division. From these visits, I selected four case study participants based on the following criteria. First, teacher-principals were eliminated if they were unable to participate. One teacher was beginning a leave and another teacher was returning from a leave, leaving six. Second, teacher-principals were eliminated if they had little colony teaching experience. As a minimum, the teacher-principal was required to have taught at a colony school in at least the current and preceding school years. This condition ensured that teacher-principals had colony teaching experience and had acquired some knowledge of the Hutterite colony's culture. One teacher-principal was new to the position, so the pool was narrowed to five. Third, a representative sample of the genders was sought. The eight colony schools had three male and five female teacher-principals. Of the remaining five teacher-principals - three males and two 
females - one male teacher-principal was eliminated to achieve an even gender ratio.

The data collection process entailed (1) observing, participating with, and interacting with teacher-principals in their classrooms, (2) informally and formally interviewing the teacherprincipals, and (3) examining processes and procedures related to school administration, student management, staff relations, and leadership. Observations spanned one full week at each school. For interviews, a minimum of three were conducted with each teacher-principal. The first two occurred at the school at different junctures in the observation week. The first - approximately one hour-introduced the purpose of the research, established a record of the participant's experience, and probed the nature of the school setting. The second interview - also approximately one hour-provided an opportunity for the teacher-principal to describe the students and the colony; clarify issues about the school and the students, resources, budget, setting, and future enrollment; and consider any open-ended issues specific to the school and colony. The third interview occurred a week to ten days later. The interview was approximately 90 minutes long, off-site, and not during school hours. The goal was to permit the participants to reflect on their experiences and provide details of their position. A total of fourteen hours were spent interviewing the teacher-principals. Not accounted for in this number are the numerous informal discussions held before school and during class, recess, and lunch.

All-in-all, the data collection period spanned four months. Interview transcripts and field notes were inductively analyzed through thematic coding. The goal of thematic coding is to identify emerging themes and patterns. Categorization, grouping, and comparison of data were completed in NVivo, a qualitative data analysis program.

\section{Results}

\section{The Colonies and Their Teacher-Principals}

The ages and career stages of the teacher-principals varied. The province's teachers are required to be neither experienced nor specifically licensed (other than possessing a Saskatchewan Teacher Certificate) to be appointed as the teacher-principal of a colony school. Two had been assigned to a Hutterite colony as their first full-time teaching assignment after college graduation. Two had prior experience working at other schools, teaching various grade levels, and working concurrently as a teacher and principal. Student enrollments at the four Hutterite schools ranged from six to 30 students.

\section{Mara Valley Colony Teacher-Principal}

Daniel, the teacher-principal of Mara Valley Colony School, had taught for 23 years and had been the teacher-principal at Mara Valley for eight years. Daniel was fluent in German. Daniel had begun his career as a classroom teacher in an English school and had served as a vice-principal in a rural K-12 school. Of the four teacher-principals, only Daniel had previous school administrative experience. Daniel described himself as a "late starter" because his 
teaching career began when he was thirty years old. Prior to teaching, Daniel had earned a master's degree in divinity from a California university and had served as a youth pastor and a minister in a church with Anabaptist traditions. Daniel's church background was a source of inspiration to him in his interactions with the students and the colony members. I felt that Daniel was proud of his theological background and experience. He spoke with pleasure of the robust theological discussions he had with the colony's men. Daniel and the elders had determined that they had common ancestors reaching back a number of generations to the colony's European origins.

\section{Big Hill Colony Teacher-Principal}

Shirley was the teacher-principal of Big Hill Colony School. She had 13 siblings and was raised on a farm in rural Saskatchewan. Shirley had strong religious convictions and was active in her Laestadian Lutheran church community. By paying attention to the manner by which Shirley described her religious background and beliefs, shared themes with the Hutterites (e.g. avoiding worldliness) were apparent. Shirley felt that her background provided a strong connection to the colony and its beliefs. For example, early members of the Laestadian Lutheran church community had arrived from Scandinavia and had settled in organized settlements in an isolated region of Saskatchewan. Time and generations passed, and the spread of the population in Saskatchewan diminished the settlements' isolation, similar to what is occurring to the Hutterites. Shirley had taught kindergarten for five years at a rural school prior to her seven years at Big Hill Colony, and she had taught in Europe for one year.

\section{Valley Creek Colony Teacher-Principal}

Bill was in his first year teaching at Valley Creek Colony; however, he was an experienced Hutterite colony teacher. Bill had been the teacher-principal for seven years at another Hutterite colony, a school with 31 students, before transferring to Valley Creek. Bill's organizational skills had been instilled in him partly from working with a large number of students at his previous school. Similar to Daniel, Bill's facility in German supported him in the colony setting. Bill had taught in two rural K-12 schools preceding his first colony teaching position.

Bill was 48 years old. Like Daniel, he had not started teaching until he was 30 years old. Besides teaching, Bill had many other skills and hobbies. He owned 13 Ducati motorcycles and restored vintage automobiles. Some of his vehicles and motorcycles were stored in one of the colony barns and he was free to use any of the colony's tools and equipment. Bill was a skilled mechanic and carpenter and he ran a successful part-time business doing house renovations and constructing basement family rooms and garages. Bill stated that he did not really need the teaching job, but he loved his work. Bill had purchased a five-acre plot of lakefront property near the colony and he was planning to build a home and move his family there. On the weekend, some of the colony men and boys helped him clear trees and brush from his acreage. Valley 
Creek Colony had a small concrete company and they were going to pour the foundation of Bill's new house. He received a great deal of satisfaction as a result of his interactions with the colony and the impact he had on its young people. On one occasion, Bill said, "You have these kids forever."

\section{Poplar Grove Colony Teacher-Principal}

Margaret had been the teacher-principal at Poplar Grove Colony for five years. It was her first full-time teaching position after university graduation. Prior to coming to Poplar Grove, Margaret was a substitute teacher for the School Division. Margaret had grown up living next door to Poplar Grove Colony and many of the colony members had known her and her family for many years. Margaret's parents had owned and operated a store in the nearby town, and the colony had patronized the business for many years. Margaret's father often assisted in her classroom. He had also provided an external work setting that allowed some of the colony boys to complete a high school credit in Work Experience 10. When I walked into the school on the first morning of my course of observations, Margaret was vacuuming the classroom. She did this on a daily basis due to the lack of regular janitorial service, she said.

\section{Major Themes}

Three themes emerged from the thematic coding process: the management of multiple and competing role expectations, the primacy of teaching, and distant relations between the school and school division / province.

\section{Theme One: Managing Multiple Responsibilities}

A common concern of the teacher-principals was the challenge of balancing their two professional roles. The four colony teacher-principals felt harried due to the combined demands of educational and administrative roles. There was no disagreement among the participants that administrative responsibilities were increasing and no extra time or resources were being provided. Yet, interviewees continued to treat teaching as the primary role and the responsibilities associated with administration as secondary and therefore as the source of strain. Administrative responsibilities competed with teaching, not vice versa.

Although formally stated role descriptions and expectations are open-ended and ambiguous (e.g. "The principal will complete other duties as assigned by the School Division"), the responsibilities of a school administrator are many. When asked about who does administrative duties, staff supervision, and other administrative functions, Shirley repeated the same refrain: she does them. The teachers stated that they supervised their staff and assigned tasks, completed and submitted the school's budget, and liaised with the community, to name a few. Yet, the teachers have no administrative release time and no actual time during the school day devoted to administrative tasks. Consequently, teachers often postponed what administrative duties they could to later, as Daniel described: 
As an administrator on a colony, you're teaching full time, so although your responsibilities are substantial in the administrative sense, your day is spent mostly in consideration of the instruction and management of the students in your class, in the school, and their issues. The administration almost fully is done after hours in the evening or after school, and there is no administrative assistant. All that work that has to be done is not done during instructional time.

Some tasks were handled during lulls in the day, such as catching up on phone messages. During instruction, nobody was available to answer the school's phone; everyone was workingteacher, assistant(s), and students. If possible, an older student would answer the phone. Usually the phone call went to an answering machine and a staff member listened at recess, during the noon hour, or at the end of the day. Routine janitorial and maintenance work was also postponed. "There is less support in certain areas like daily janitorial work," said Daniel. "We do our own maintenance chores except on the weekend when the girls come in and do some of it."

Other administrative work had to be taken home. Big Hill Colony had poor internet access and doing online work from school was not an option. Shirley had to complete her computer-based administrative duties at home rather than at school:

I don't have internet at school, so any of those things that need to be done are going to be done at home. All my administrative work is done on my own time at home, after school hours, or on a Saturday, or something like that. We have an internet USB stick at the colony, but it is so slow that it is not worth waiting for it to work. That's why I do everything at home where I have a regular internet connection.

Some administrative responsibilities could not be postponed at all but had to be reduced or sacrificed since they demanded attention during class time. For example, teachers were limited in the time they could supervise and assist staff members while teaching, as described by Daniel:

I have three other staff members. I am responsible for them and I am teaching full time. I can't just go and walk around and see what is going on in every classroom. However, I do try to break away as much as I can to find out what is going on. Because we are in a small building, we are always having conversations about all the students and what is going on in the other classrooms. I am still very aware of what occurs in the whole school even if I am not doing formal observations.

Upon taking the job, three of the four teachers had to learn how to manage administrative responsibilities. Only Daniel had school administrative experience (as a vice principal) prior to a colony school appointment, likely helping him adjust to the teacher-principal job. Margaret, on the other hand, had little preparation for teaching or administering a colony school. Working on the colony as a neophyte teacher and having no full-time teaching experience or any administrative experience, Margaret nonetheless managed to adapt: 
I have never been in an administrative position, although this one is not huge. Having a few confrontations, resolving conflicts, dealing with people, and even dealing with people who have more experience than I have is not too much of a burden.

While not an insurmountable burden, the many responsibilities are still a heavy load. In addition to both the teacher and principal role, teachers had to take on a third hat, the administrative assistant, addressing the clerical demands and responsibilities of the school, the colony, the Division Office, and the Ministry of Education. "I know many other administrators do not have to do administrative assistant work," said Daniel, "so there is a great range of things that one learns to do that falls into completely different occupational categories." And yet, the teachers recognized that these extra assistant duties are somewhat of a tradeoff for fewer lead administrator duties, like managing high schools, as Shirley noted.

One has to learn all the roles of the administrative assistant as well, [but] there may be fewer administrative tasks of some kinds, like supervising work experience or providing high school credits, at least at this time. That could change in the future and it already has on some of the colonies in our school division.

Shirley, likewise, did not overly begrudge the extra responsibilities and her attitude reflected a strong service-oriented manner. She completed her tasks, seeing the arrangement as fair.

If things need to be done, these are duties that need to go to the administrator. In other schools, a lot of those duties can go to the vice-principal or the administrative assistant, but that doesn't happen in our situation. If something needs to be done, I have to do it. I don't feel like it takes a lot of time and I feel that I'm fairly compensated with the basic principal administrative allowance I receive.

And the teacher-principals are paid accordingly. As compensation for being assigned the duties of the principal, each colony teacher-principal received a basic administrative allowance as negotiated in the teachers' province-wide collective agreement $(\$ 7,576$ for the 2015-2016 school year).

Yet, even with an increased pay, the arrangement still did not make up for a lack of resources. When set against other public schools in the district, the Hutterite schools seemed to have proportionately fewer administrative resources, and some teachers questioned this. Margaret recognized that larger schools had greater responsibilities, more staff and students, but she had obligations too:

Quite often I am visiting another school that is nearby and I see the administrators there doing a lot of work. Yes, they have a great deal more responsibility because they have more staff. Yes, they have a lot more students. There are students with diverse needs in their school; however, I have students with diverse educational needs in my school. 
And some of these needs go beyond the typical learning variation present in any classroom. While the Hutterite children are designated as English Language Learners (ELL) — as their mother tongue is German - the schools did not receive any assistance from external educational consultants.

In summary, while the extra administrative load does put some strain on the teachersand the teacher-principals would all rather give their full time to teaching - they have found ways to juggle the extra duties, although not without anxieties for what additional loads are ahead.

\section{Theme Two: The Primacy of Teaching}

In spite of the many demands, the teacher-principals were quite dedicated to educational objectives. Teaching was their first priority; it was the reason why they were on the colony. In interviews, the teachers described their attention to education, to the teaching process, and to the minutiae and daily routines required to work with colony students and the community. In my observations, the primacy of teaching was evident in the teachers' interactions with students and the attention the teachers paid to the daily details of a classroom.

Although the teachers were likely not preparing their students for post-secondary training, or even graduating from high school, there was a concerted effort and an earnestness to encourage the students to do excellent work and to prepare them for their future roles in the community. "You 're making little farmers," said Bill informally on one occasion. The teacherprincipals expressed a desire for their students to be life-long learners and to be able to adapt to a changing Hutterite and outside world. Likewise, the teacher-principals also adapted their curriculum with enthusiasm. They prioritized the implementation of new curricula and other provincial and local initiatives - significant in number and scope - throughout the study period.

The personal and professional development experience of teaching at a Hutterite school gave the teachers a sense of satisfaction. All of them were able to connect interpersonally with the colony culture. At one level, they connected ideologically. The teacher-principals described and recognized the Hutterite colony, first and foremost, as a religious community. They believed in the goals of the colony, they endeavored to understand Anabaptist traditions, and they were sympathetic to the challenges faced by the colony and its residents. Shirley's religious nature facilitated her sense of belonging and empathetic ability: "I have a strong religious identity which I found is helpful teaching on a Hutterite colony because they are quite religious in their daily lives." Should the Hutterite school teachers lack sympathy, empathy, or a willingness to understand the colony's religious nature, they would likely find it difficult, if not impossible, in fulfilling their professional responsibilities.

Teachers also connected interpersonally and culturally with the colony. Daniel described how teaching in the colony school brought richness to his life. He was pleased with the contributions he made to the lives of the Hutterite children and their community. He felt 
sometimes that he had more in common with the Hutterites than with people in his own neighbourhood:

I feel a great deal of kinship with the people. In some ways I know there is a culture gap, and there are things that I have to forgive and forget, but in some ways there are larger cultural gaps for me than being in this culture. Different parts of urban life might seem more remote for me than being part of the colony life during the school day.

The commitment to teaching and the investment / connection they felt with the Hutterite colonies helped them overcome some colony school-specific difficulties. Some difficulties are typical of any school, including variation in family interest in the educational process and the amount of time lost over the summer. Said Margaret,

It varies from home to home as to what kind of drop-off there is over the summer holidays. Some homes aren't much enriched over the summer and you have to go back quite a few steps. But in some homes they make quite a few gains, even during the summer.

Indeed, summer and other holiday experiences varied from family to family. Some families travelled to visit relatives in the summer or during holidays, others stayed on the colony.

Other difficulties are specific to the Hutterite colony system and culture. For one, new teacher-principals have a steep learning curve coming into a one-room colony school. The participants agreed that teaching in a one-room school environment was taxing. They were responsible for all students, subjects, grades, and contingencies. The teacher taught each subject for each grade, unless the students were registered in an on-line course or had an itinerant teacher for high school courses. Organizational and classroom management skills were paramount, and a new teacher to the colony school would find the role challenging. Bill described his first experiences teaching on a Hutterite colony and the necessary adjustments and adaptations to his teaching style:

I know that in the first six months my head was spinning because I was trying to teach like at a regular school, trying to fit all these subjects in and stuff. Like, hold it, how do I teach even after grouping them into three or four groups and you try to get them all going on science and stuff? It is like, "This is not working." It was my job and in the end a lot more rewarding. I had 25 kids and [I was] so stressed.

Bill was being challenged as a teacher because he was teaching primary grade students rather than the older ones he was used to:

I have a new respect for the lower grades elementary teachers, but it has added a different dimension to my teaching. Working with that younger age group and taking them right from grade one like I have this year, you definitely get a well-rounded experience out 
there.

Teacher-principals also faced difficulties with the school being constrained by colony demands, as with their no-homework policy. While the teacher-principals believed that their students should do homework to advance their learning and to complete assignments, the colonies did not expect the children to do homework. After school and into the evening, colony children are busy completing chores, going to church, and tending to other colony-related activities. Colony commitments trumped school.

Teacher-principals also had to synchronize the school schedule with the colony schedule. Synchronization allows the students to eat their meals with their families and the rest of the colony. A student is not expected to stay in school at lunch time or after school (e.g., the student has incomplete work or a detention), and colony tasks and commitments take priority over student-related duties. The teachers did what a flexible, sensitive, and adaptive teacher would do: give no homework or detention. Not that they were ever enthused about this, as Margaret states, "Because they don't do homework, they don't progress as quickly even though they are as bright as other kids." But the teacher-principals nevertheless accepted the colonies' approach to school.

In spite of these challenges, the teacher-principals showed much evidence of enjoying teaching. Daniel's position on the Hutterite colony was "the best thing that has ever happened to me professionally." Daniel regarded his work as more than just a job:

Having come to the colony I think it's tied together a whole bunch of things about who I am. It has given me a feeling of competence, and a feeling that I am who I am supposed to be. At other points in my career, whether I've been in leadership or not, one is often typecast or boxed in or restricted or controlled by other factors, for instance teaching [certain] courses from year to year. One may be teaching different grades from year to year or you may be seen as the English teacher, the history teacher, the grade seven teacher, or something like that. However, in this role I don't have to see myself in any particular way but only as a principal and teacher who is responsible for the whole school. I get to work with students of all ages, I get to work with adults, I get to teach all the subjects, and I have a great sense of responsibility, which gives me a great feeling of reward because I'm in control of so many things.

In summary, while the multi-graded colony school setting presented both common and unique challenges, the teacher-principals' commitment to teaching and a personal sympathy with the colony made teaching successful.

\section{Theme Three: School Division and Provincial Relations}

The remoteness, smallness, and uniqueness of colony schools impacted relations between the teacher-principal and the school division / the Saskatchewan Ministry of Education. Central office was relatively uninvolved in the peculiarities of the colony schools. On the one hand, this 
made it more difficult for colony schools when faced with uniform district- and province-wide changes for all public schools and with attaining needed resources. On the other hand, the noninvolvement gave the teacher-principals more control over localized day-to-day operations.

The physical and conceptual distance between the colony schools and the school division administrators sometimes made programs and practices irrelevant or tedious for colony teacherprincipals. For example, monthly School Division-level administrative council meetingsattended by all principals and School Division administrators-lacked relevance to colony teacher-principals, who viewed colleagues as too unfamiliar with the roles and settings of colony teachers.

Uniform policies imposed across the district or province can also make for difficulties. The teacher-principals believed that the changing expectations and increasing number of tasks assigned by the School Division and the Saskatchewan Ministry of Education contributed to strain. Policies designed primarily for larger public schools must also be implemented in colony schools. For example, colony schools once kept students' school records and documents in a filing cabinet in the classroom or in the school's office. This was sufficient. However, a new student information policy now requires each student to be directly registered with the Ministry of Education. The student receives a life-long student number in kindergarten. Previously, students only received a student number when they reached grade ten, and it was primarily used to record high school credits for matriculation. Teacher-principals could avoid student numberrelated responsibilities since few colony students progressed past grade eight. Now that all students have numbers, the teacher-principal must proactively submit information.

An added challenge for the teacher-principals was that the information submission process was completed online. Perhaps this was an improvement in larger public schools. Colony teacher-principals, however, were unfamiliar with the process and they felt that their computer skills and technology resources were inadequate. The recently implemented student information system was accessed by the teacher-principals through a computer database known as the Student Demographic System (SDS). SDS was user-friendly if you used it on a regular basis, as with the administrative assistant in other schools. However, the Hutterite teachers may use the SDS once or twice a month during the school year. Due to the software's complexity, and because the program changed periodically with upgrades and innovations, re-education was required practically each time they used it. Shirley echoed the comments of the other teacherprincipals respecting the completion of administrative tasks that utilized School Division and Ministry of Education software:

I wouldn't feel that I'm oppressed by my administrative duties, but sometimes the other colony teachers and I are frustrated because we don't have a secretary that can enter SDS or Navision [the School Division's budget management and maintenance software program]. In another school the administrative assistant is entering SDS and Navision for many teachers and she's very familiar with what's going on. But I was running SDS and 
Navision and doing it once a month for one or two days, and maybe for a month or two I wasn't doing it at all. I would forget what I needed to do from this month to the next month, or the software was changed. It's like, "Oh goodness, what step do I follow now?" That was a little bit frustrating and that can be exasperating because I don't have any support in my building, although I do call the Division Office for help.

While the distance from school policy makers sometimes comes at a disadvantage, other times it is an advantage. The teacher-principals perceived that the school district had an attitude of benign neglect toward colony schools. Purposeful visits from the Division Office occurred if necessary (e.g., budgeting and staffing discussions). Yet, due to the colonies' physical isolation and the rural gravel roads that led to them, and the presence of so few staff at the school, it would take a dedicated Division Office administrator to regularly visit the colony schools. Interestingly, the colony teachers viewed the lack of visitation and supervision as a back-handed compliment that sublimely implied satisfaction with their work. The teacher-principals were less disappointed with the limited visits as long as the needs of the school and staff were met through attention to budget, staffing, and resources.

If the teacher encountered a serious issue, the proper authority appeared at the school or communicated with the teacher through phone or e-mail. However, the participants believed that few of the school division senior administrators had a sound knowledge of the idiosyncrasies and related needs of colony teacher-principals. Said Margaret,

The Division Office has good intentions. I really do appreciate when they give us the flexibility to adapt. I think some people there have good intentions, but I think some people don't pay much attention. I think we just float under some people's radar most of the time. I don't feel that people in the Division Office are out in the schools enough to understand what goes on in a colony school on a daily basis.

The participants believed that it was valuable for the School Division to develop a greater awareness of the colony schools. Significant differences existed between colony schools and the schools in the suburbs and small towns.

\section{Discussion}

The four experienced colony teachers articulated the immense satisfaction they get in their work; however, they also voiced concerns about certain obstacles. Here I provide two policy-level recommendations: (1) recruit teacher-principals who exhibit cultural and relational competence; and (2) integrate teacher-principals into the district / administrative processes to provide the best support for colony schools.

\section{(1) Cultural and Relational Competence of New Teacher-Principals}

While the teacher-principals showed strong personal support of Hutterite culture, they 
were not Hutterite. A systemic ethnic, cultural, and language schism existed among the teacherprincipals, the colony, and the students. Nevertheless, they managed to work with these differences. New teacher-principals should also possess such cultural and relational competence.

Culture symbolizes the unified configuration of human views, communications, activities, customs, beliefs, values, and foundations of a racial, ethnic, religious, or social group. This perspective rests upon an assumption that "there are certain psychological characteristics that all ethnic and culturally different [people] share" (Diller 2004, 5). Highlighting the importance and necessity of facilitating cross-cultural understanding and intercultural communication, Ting-Toomey $(2012,3)$ wrote:

With rapid changes in global economy, technology, transportation, and immigration policies, the world is becoming a small, intersecting community. We find ourselves in increased contact with people who are culturally different, working side by side with us.

From workplace to classroom diversity, different cultural beliefs, values, and communication styles are here to stay. In order to achieve effective intercultural communication, we have to learn to manage differences flexible and mindfully.

To adopt the mindset required for success in cross-cultural classrooms, cultural empathy is a requisite skill. Cultural empathy helps produce a supportive classroom climate and culturally relevant pedagogy. Teacher-principals should also be comfortable working with a high degree of agency (Priestley 2015), as were the four teachers in this study. The teacher-principals' strong belief systems, dispositions, and personal capacities strengthened their performance.

The principle of "cultural intelligence" also provides a useful measure for assessing prospective teacher-principals. Cultural intelligence is "the prevalence of cross-cultural understanding and an ability to live and work productively and harmoniously with people having very different values, backgrounds, and habits" (Deardorff 2009, ix). Cultural intelligence is perceived as an understanding and appreciation of one's cultural identity, the similarities and differences between cultures, and the utilization of one's knowledge of culture to maintain active relations with and students (Thomas 2006).

Cultural empathy and cultural intelligence help teachers relate across the cultural boundary. In his work on cross-cultural leadership, Manning $(2003,21)$ argues that technical competence and organizational experience are not enough to be an effective leader. Rather, leaders need to possess "relationship competence and openness to new perspectives." According to Terpstra (2002), relationship competence is characterized by understanding the behaviour of others, possessing communication skills, having sociability, being an encourager, being motivational, being a confidence builder, and being positive and dynamic. Terpstra described the ability to adapt to new cultures and to reconcile the differences between yours and theirs as to "think in both directions," taking a reverse view to the conflicting values.

There are more than 60 Hutterite colonies in Saskatchewan and we may assume that each 
has a school. Therefore, there are more than 60 non-Hutterite teachers. Presently, there is no dedicated education course at either of Saskatchewan's two universities for pre-service teachers considering this cross-cultural career path. To enhance cross-cultural skills, education tracks should consider incorporating courses addressing Saskatchewan's cultures, including the Hutterites.

\section{(2) Facilitate Administrative Support for Colony Teacher-Principals}

The teachers were concerned about professional, cultural, and physical engagement in interaction between themselves and other principals, School Division administrators, and Ministry of Education personnel. To increase connections, knowledge, and understandings, colony schools could host divisional administrators' meetings. After all, English schools, guided by Hutterite children, often tour the colony during the school year. Why not provide this for school administrators?

One such visit was recorded as a success. When a Hutterite school hosted a divisional administrators' meeting, according to Kleinsasser (n.d., p. 10), "the administrators could not get over the generous size of rooms. The visiting principals expressed surprise at the educational and multimedia resources that were available to enhance instruction and to accommodate diversity in learning styles." Principals could observe their colleague's school, share ideas, and be introduced to colony culture.

As administrative responsibilities at the colony school increase, understanding is needed at the district and provincial level. Otherwise, the quality of colony student instruction and administration may be inhibited as time pressures and personnel fatigue diminish employees' interest in the colony teacher-principal position.

\section{Conclusion}

In conclusion, the teacher-principals considered their positions an inspiring personal and professional experience. The colony and its school were interesting and enriching. Daniel stated this perspective best with his personal assessment:

One should see the role as great professional development for managing a multi-grade classroom and organizing yourself. Instruction and the administrative tasks take a great deal of organization and planning. However, I think there is nothing like it, even for its own sake, or for what you may do later on in your career. You have to learn to teach at so many different levels, so many different subjects, to reach across barriers that you didn't know existed, to try to connect with kids and to try to help them learn a new language. Professionally, being a Hutterite principal-teacher is just about the best thing one could do to become a great teacher. 


\section{Endnote}

${ }^{1}$ Contact information: William Rodger, s905-737 Humboldt St., Victoria, BC V8W 1B1, Canada; wrodger1@uvic.ca

\section{References}

Deardorff, Darla. 2009. "Preface.” Pp. xi-ixv in The SAGE Handbook of Intercultural Competence, edited by D. K. Deardorff. Los Angeles, CA: SAGE.

Diller, Jerry. 2004. Cultural Diversity: A Primer for the Human Services. Toronto, ON: Brooks/Cole-Thomson Learning.

Erlandson, David, Edward Harris, Barbara Skipper, and Stove Allen. 1993. Doing Naturalistic Inquiry: A Guide to Methods. Thousand Hills, CA: SAGE.

Guthrie, James, and Patrick Schuermann. 2010. Successful School Leadership: Planning, Politics, Power, and Performance. Toronto, ON: Allyn \& Bacon.

Kleinsasser, Raymond (n.d.). Hutterite Education: Growing Pains. (proxycheck.lib.umanitoba.ca/faculties/education/media/Raymond_Kleinsasser_06.pdf)

Manning, Tracey. 2003. "Leadership across Cultures: Attachment Style Influences.” Journal of Leadership \& Organizational Studies, 93:20-30. http://dx.doi.org/10.1177/107179190300900304

Merriam, Sharon. 2009. Qualitative Research: A Guide to Design and Implementation. San Francisco, CA: Jossey-Bass.

Priestley, Mark. 2015. Teacher Agency: What Is It and Why Does It Matter? BERA British Educational Research Association, London. (https://www.bera.ac.uk/blog/teacheragency-what-is-it-and-why-does-it-matter)

Silverman, David. 2004. Interpreting Qualitative Data: Methods for Analyzing Talk, Text, and Interaction (2 ${ }^{\text {nd }}$ ed.). Thousand Oaks, CA: SAGE.

Terpstra, Vern. 2002. "Review of Hampden-Turner and Trompenaars: Building Cross-Cultural Competence: How to Create Wealth from Conflicting Values." International Marketing Review 192(3):204-205. http://dx.doi.org/10.1108/imr.2002.19.2.204.1

Thomas, David. 2006. "Domain and Development of Cultural Intelligence: The Importance of Mindfulness." Group \& Organization Management 311:78-98. (gom.sagepub.com/ content/31/1/78.short) http://dx.doi.org/10.1177/1059601105275266

Ting-Toomey, Stella. 2012. Communicating across Cultures. New York, NY: Guilford Press. 